\title{
The Contribution of Playing Music Notation toward the Development of Sound Perception on Students with Hearing Impaired
}

\author{
Martias Z. \\ Special Education Department \\ Faculty of Education Science \\ Padang State University \\ Zmartias057@gmail.com
}

\begin{abstract}
It can be said that Hearing Impairment caused anyone can not interacted with others. They don't understand the sound around them caused by a part or all of hearing apparatus can not function. The teachers and therapists, especially auditory trainer at school, have also performed their training at school and therapeutic lounge. However, auditory training of sound perception tend to step one was sound identification with there was a sound and no sound. So as to make hearing impaired students boring and their sound perception could not develop as much as possible. It seem that the development of auditory training of sound perception run in different goals. Kinesthetic and tactile are the modal in training of sound perception especially for hard of hearing and the deaf students. This means that if the hard of hearing students use a hearing aid, it is more potential at training of sound perception. For the deaf, still in training to feel the presence of sound. The training of sound perception undergoees to the degradation into maximizing the potential of residual hearing and vibration in deaf. For that, teachers and therapist should prioritize playing music notation as a way to increase sound perception of hearing impaired children. And, those are able to utilize perception into integration with community.
\end{abstract}

Keywords -- Music Notation, Hearing Impaired, sound perception skill

\section{INTRODUCTION}

Students with hearing impairments are students who experience a lack and lost of their ability to hear and different communication behaviors with normal peers. Cause of the hearing impairment, among others: (1) non-functioning part or all of the hearing instrument has had from birth; (2) there is an addition when the child produces and understands the conversation; and (3) occur at any time, which may inhibit the process of receiving information in the form of language through hearing aid either with or without the use of hearing aids to achieve a proper birth and mind life (Cruickshank and Johnson (Ed.), 1988). But that does not mean the barrier and hearing impairment has no potential to integrate with the sound world around him. The emphasis in perception of sound for hearing impairment students can be on the level of perception that may still be developed ie auditory perception through the rest of hearing and sense of vibration.

Factually, the students' perceptions of hearing impediment due to hearing impairment factor result in minimal language comprehension, so that the feeling life is less developed and not tiered. On the other hand, it is difficult to be stimulated but on the other side easily becomes excessive. Everyone without exception requires a balance of herself, one of which is not having difficulties getting into the feelings of others. Because auditory perceptions related to language acquisition will have a very important effect on the development of a student of hearing barriers in self-understanding, one of which is the understanding of language related to integration communication, can be done through continuous auditory training according to its characteristics, abilities and shortcomings.

Students of hearing impairment can perceive the sound through the rest of the hearing. In addition to using hearing aids, the child's hearing impairment will have more hearing threshold in the presence of amplification of the hearing aid. The placement and adjustment of hearing aids with the student's hearing impaired will help in terms of perceiving the sound. For deaf children, hearing aids can also help amplify sounds for detection and no sound. Through the kinesthetic and tactile senses the child is deaf hearers will perceive the sound through a sense of vibration. The palms and soles of the feet, the pore holes in the entire body of the deaf can also feel the sound of sound.

The advantages of understanding of domain knowledge on music notation (knowledge domains) in the context of this auditory training in the children of hearing impairment in receptive understanding begins through the provision of knowledge or understanding through the stages of detection of sound, identification of sound, discrimination of sound and comprehension of sound. Giving knowledge or understanding to deaf students is intended for them from the beginning have a provision to prepare the language to convey thoughts in the future. Therefore, it is the reason to take the mastery of the knowledge of music notation 
(knowledge domain) developed in the sound perception training model for the students' understanding of the language of the auditory obstacles in extraordinary schools.

Based on the background of the problems above, the students of hearing impairment can improve the understanding of auditory perception. In addition, the understanding of the music playing skills of hearing impaired students is still lacking, especially the understanding of playing simple music notation. In relation to these problems, the task of sound perception and rhyme teachers is to develop an understanding of the interest of playing simple music notation on the students of hearing impairment as early as possible.

Based on the above description, this paper helps the teachers and therapists to develop an understanding of students auditory perceptions in auditory obstacles in exceptional schools of hearing impairment children in a special program BKPBI through the enrichment of sound perception.

The implementation of auditory training aims to prepare teachers and auditory perception therapists to improve understanding of students' auditory sound perceptions and tested auditory perception skills and their vibrations. In detail the strategy recommends for: 1) improving the auditory perception of the child's auditory barriers for understanding the interest that it contains; (a) making music notation matches the amplification of adjustment of the child's hearing barrier; (b) calculating the beat of the music according to speed and metrum through the metronome instrument, and (c) create a simple musical notation game, and (2) adjust the amplification of sound with the hearing-impaired users of hearing aids and without the use of hearing aids.

\section{DISCUSSION}

Sound perception is a natural event that occurs around us. We like or unlike the sound of events will overwhelm our lives. We, normal-sounding humans have background sounds that will give a very important sense of security. With the presence of background sounds around us will bring its own sense of security. Not so for people with hearing impairment. They can not perceive background noises because of the ineffectiveness of some or all of their hearing power.

On behalf of the technological advancements developed by experts today, people with hearing impairments may be able to perceive sounds with the availability of hearing aids. This hearing aid has a increasing sound function to get to the hearing threshold of a person with a hearing loss. For people with hearing impairments when using this hearing aid will not make the hearing impaired that hearing will be normal, but this tool only functions to amplify the sound.

The sound will be understood by the hearing when it has the strength and the level of violence above the hearing threshold. Experts place the sounds of perceptual stimulation with a level of violence between $20 \mathrm{~dB}$ and $25 \mathrm{~dB}$ above the threshold. Children who have a hearing impairment with a $50 \mathrm{~dB}$ auditory threshold classification, they will not be able to perceive a sound if the level of sound violence is equal to the auditory threshold it has. To get to the auditory threshold of the child the sound hearing impediment should be amplified with hardness of $70 \mathrm{~dB}$. Deaf hearing impaired children can still perceive sounds with the material to detect sounds, ie, perceive the presence and absence of sound.

Playing music activities in the auditory perception include three basic components consisting of pitch, timing and timbre. Pitch is a musical activity associated with high and low sound, timing is something that is easily recognizable in sounds like the initial sound and the final sound; while timbre is related to the quality or color of sound or sound. For students with hearing impairment; both those who have hearing or deaf hearing, they do not experience obstacles with the elements of music that is served. They will utilize the rest of the hearing and sense of vibration, whether using amplification equipment or who do not use amplification tools.

The hearing impairment child has no barrier to access to the musical sound. By touching the sound-source (e.g. by sitting on the loudspeaker, by feeling the vibration on the floor, by touching the musical instrument or by touching his/her own or another person's voice apparatus the larynx) the child will have a contact-vibration-sensation of sounds, speech, song and music (Bang, 2009).

Playing music is a natural activity. Children with hearing impairments have no barriers to playing music. Although they are hampered by the disability, they are still able to appreciate music playing. For hard of hearing children, they are still possible in playing music scales, but for deaf children they can still play percussion instruments, especially musical instruments not pitched.

1

23

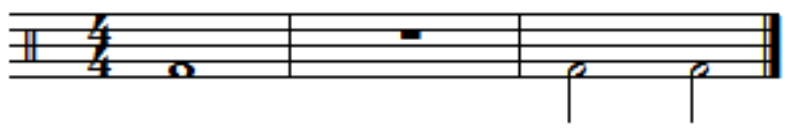

Fig 1. Music staff

Music staff above puts a time signature 4/4, then the metronome is adjusted with a time signature along with a tempo that can be monitored by the student. The first segment (1) is played by hitting the snare drum with four metronome 'sounds' starting with a sound: ting, tak, tak, tak. On the second segment there is a 'no sound sign' with the metronome beginning ting, tak, tak, tak. Next, on the third segment there are two 'sound' signs; the first sound sign by hitting the snare drum by following the metronome 
begins: ting, tak; then snare drum hit again with advanced metronome tak, tak. Thus, on the third segment there are two sounds with two metronome bands swing each time. This exercise is useful for children with a $70 \mathrm{~dB}$ threshold and a deaf threshold. Because with this threshold, the child is expected to be aware of there and no sound.

For children with hearing impairment that have a threshold below $70 \mathrm{~dB}$, they can still detect high and low sounds. Moreover, those who still have enough hearing loss to realize the sound and supported by hearing aids that have a large enough Maximum Power Output. They will be able to detect high sounds and low sounds like the staves below.
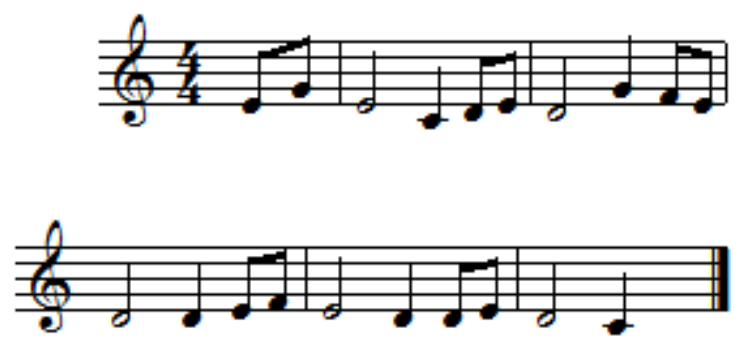

Fig 2. High sounds and low sounds

Metronome is one of the musical instruments that has the utility to measure the time travel against the beat. When the metronome is turned on, it will emit a click or a clock or metrum. For example, we will play a 4/4 metrum; then the metronome will issue a sound: ting, tak, tak, tak (four clicks). A click on the metronome will raise a loud enough sound for auditory training. Also, the metronome tool in auditory training is used for the exercise of counting sounds.

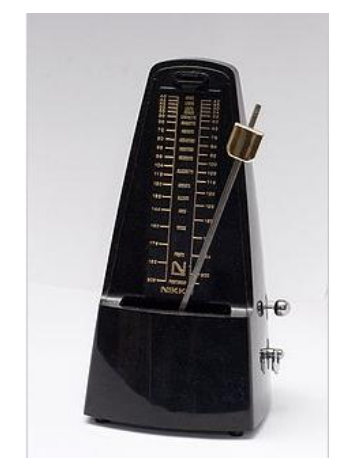

Fig 1. Metronome

\section{CONCLUSION}

Hearing impediment is a situation of having a hearing impediment in such a way; ie, less hearing and deafness with the category of light, medium, heavy and total, so that for the development of language needs help coaching auditory perception as early as possible so that it can integrate with the surrounding environment.

Auditory training by playing music does not become unreasonable to persons with obstacles and becomes an obstacle for hearing impaired persons. Through the rest of the hearing and sense of vibration owned make the modalities to perform music playing activities. Development of auditory perception training sound through music, we can use rhythm as a tool to develop memory and intelligence. Audit training should be in line with 'coaching in the intentional or accidental intake of sounds, so that the auditory hearing and vibration of the child's hearing impediment can be best utilized to integrate with the surrounding world full of sounds' (Yuwati, 2000).

Therefore auditory training is very influential on the process of language development of children obstacles hearing. Implementation of auditory training for children with hearing impediments should be well programmed according to sound perception stages: detection, discrimination, sound identification and comprehension.

\section{References}

Bang, Claus. 2009. A World of Sound and Music: Music Therapy for Deaf, Hearing Impaired and Multi-Handicapped Children and adolescents. 91-103. Denmark: Soundergade 61, DK-9480 Lokken.

Fix, Julie. 2008. The Use of Music Education in Oral Schools for Children Who Are Deaf And Hard of Hearing. Washington University School of Medicine. Digital Commons@Becker 
Mapolisa, Tichaona \& Tshabalala, Thembinkosi. 2013. The Impact of Inclusion of Children With Hearing Impairment Into Regular Schoos: A Case Study of Dakamela Primary School in Zimbabwe. International Journal of Asian Social Science. Pp 1500-1510.

Moore, David R. \& Sygnal Arnitay. 2007. Auditory Training: Rules and Application. Article. Seminar in Hearing. Page: 99-109.

Spencer, Patricia Elizabeth \& Marc Marschark. 2006. Advances in the Spoken Language Development of Deaf and Hard-ofHearing Children. Oxford: Oxford University Press 